\title{
A utilização das redes sociais na modalidade EJA
}

Rute Vera Maria Favero*

\begin{abstract}
Resumo:
O presente trabalho analisa a inserção e a importância das redes sociais no ambiente escolar da Educação de Jovens e Adultos (EJA). Tem como premissa a necessidade de inserir as redes sociais dentro de um contexto escolar a fim de que os alunos saibam como utilizá-las a seu favor na obtenção de informações, evitando a disseminação de notícias falsas (fake news). Foram aplicados quatro questionários, ao longo de 3 anos, com alunos do Ensino Médio, da modalidade EJA, do Colégio de Aplicação da Universidade Federal do Rio Grande do Sul (CAp-UFRGS). Foi constatado que o uso das redes sociais é importante devido a presença no contexto social dos alunos, e deve ter como propósito o ensino conscientizador e crítico sobre a obtenção de informações.
\end{abstract}

\section{Palavras-chave:}

EJA. Redes sociais. Informação. Educação.

\begin{abstract}
:
The present study analyses the insertion and importance of the use of social media in the school environment of the Educação de Jovens e Adultos ${ }^{* * *}(E J A)$. The premise is to investigate the need for social media introduction in the school context. Manly to show the students how to use social media in their favor to obtain information and to help them to avoid the dissemination of fake news. We used four questionnaires, between 2017 and 2019, to get the analyzed data. The participants were students from the high school EJA from the Colégio de Aplicação of the Universidade Federal do Rio Grande do Sul (CAp-UFRGS). The data proved that the use of social media is relevant mainly because of its presence in the students' social context, and it must be awareness-raising and critical teaching about information and where they search for it.
\end{abstract}

\section{Keywords:}

Adult literacy. Social media. Information. Education.

\footnotetext{
* Doutora em Educação pela Universidade Federal do Rio Grande do Sul e Università Roma Tre. E-mail: rute@ufrgs.br. ORCID iD: https://orcid.org/0000-0001-9800-7013.

** Graduanda em Letras na UFRGS. E-mail: raissawasemcardoso@hotmail.com. ORCID iD: https://orcid.org/0000-0001-5255-4062. *** Modality of teaching in Brazil created to educate the part of the population over 18 years old that did not finish school.
} 


\section{Introdução}

O futuro da sociedade depende de cidadãos engajados, informados e que saibam pensar criticamente; e, para isso, precisamos que as pessoas — jovens e adultos - tenham a disposição, no ambiente escolar formal - e não formal - o ensino, de tal forma que consigam lidar com as informações disponíveis nas redes e que consigam, além de obtê-las, compreendê-las. Por isso, é recomendável que se coloque em prática uma das frases filosóficas mais conhecidas pela humanidade: "se penso, logo existo", que está presente no texto Discurso do Método de Descartes. Tal lógica implica que o ser humano tem que se entender como ser pensante para poder criticar e pensar por si próprio, como afirmam Vieira e Santos,

[...] com toda categoria com relação a autoconsciência para o pensar e refutar ideias lançadas ao meio social em que se faz presente a civilização humana. Com isso fica claro a intenção de Descartes com relação a seu pensamento inovador para a época de elevar o homem a um nível racional descobrindo a si primeiro para logo após questionar sua realidade. [...] a primeira filosofia para Descartes é a consciência de si mesmo, ou seja, para que o pensamento racional aconteça é necessário primeiramente o ato de pensar e esse pensar parte do sujeito pensante. (VIEIRA; SANTOS, 2016, p. 2).

Contudo, com o advento da tecnologia e da internet, é necessário que o sujeito se entenda também como um ser pensante, integrante da sociedade digital, não mais, apenas, integrante da sociedade física. Sendo a escola um dos locais onde as pessoas passam mais tempo durante a vida, gastando, pelo menos, $10 \%$ de sua vida dentro dela - levando em consideração a expectativa de vida, no Brasil, de 76,3 anos (IBGE, 2019) - , ela toma para si o princípio de ensinar o indivíduo a viver em sociedade (segundo a Lei no 9.394/96, conhecida como Lei de Diretrizes e Bases da Educação Nacional [LDB] [BRASIL, 2017]). Então, se deduz que a escola deve tratar, também, sobre o uso da internet e suas aplicações para que se construa uma sociedade que saiba usufruir ao máximo dos recursos oferecidos pela WEB.

Entretanto, é, inclusive, afirmado na LDB que a família também deve se encarregar da educação do aluno; sendo assim cabe aos pais reforçarem o que é visto na escola e, por isso, a família também deve ter acesso a esse conhecimento. As classes sociais que mais têm filhos no Brasil, de acordo com a quantidade de pessoas, são C, D e E, atingindo 85,6\% da população (BÔAS, 2019), e são, principalmente, para estas que a EJA se direciona. São as classes sociais que mais se encontram à margem da sociedade e deveriam ser um dos principais objetivos da inclusão digital, uma vez que elas precisam entender como usar a tecnologia a seu favor, principalmente para obtenção de conhecimento e para se sentirem pertencentes a este mundo, que, para muitos, é novo. A Declaração de Jomtien afirma que

[...] a escola (de ensino EJA) deverá incorporar efetivamente os conhecimentos - conteúdos e competências - necessários para que o indivíduo possa desenvolver-se física, afetiva, intelectual e moralmente, a fim de desempenhar-se com autonomia no âmbito político, econômico e social no seu contexto de vida. (OLIVEIRA, 2010, p. 107).

Dessa forma, a EJA deve atender também à demanda por ensino e inclusão digital que a população menos favorecida traz. Deve-se adotar medidas que permitam combater a desigualdade existente no que tange à educação. É importante lembrar que "a forma como a educação formal está organizada, muitas vezes, tem promovido mecanismos de exclusão social e pouco acesso à cidadania” (FAVERO, 2016, p. 42). Na esteira da exclusão social vem a exclusão digital, portanto, mesmo sabendo que muitos ainda enfrentam dificuldades diversas, como equipamentos (celular, computador, etc.) inadequados ou falta de acesso à internet, o espaço virtual não pode ser ignorado como um espaço possível para a aquisição da aprendizagem. Nesta linha de pensamento, o relatório Delors sugere que as TIC 
[...] poderão constituir, de imediato, para todos, um verdadeiro meio de abertura aos campos da educação não formal, tornando-se um dos vetores privilegiados de uma sociedade educativa, na qual os diferentes tempos de aprendizagem sejam repensados radicalmente. Em particular, o desenvolvimento destas tecnologias, cujo domínio permite um enriquecimento contínuo dos saberes, deveria levar a reconsiderar o lugar e a função dos sistemas educativos, na perspectiva de uma educação prolongada pela vida afora. (DELORS, 1998, p. 66).

Segundo a Pesquisa Anual por Amostra de Domicílios (PNAD) (IBGE, 2018), dos 831 mil alunos da EJA, $54,9 \%$ da população é constituída por mulheres e $65,7 \%$ por pretos e pardos, além de 51,5\% estarem acima dos 25 anos. Outra pesquisa, realizada pela BBC (IDOSOS..., 2019), aferiu que as fake news ${ }^{1}$ são mais suscetíveis a serem espalhadas por pessoas da classe C, D e E, que fazem parte da população menos favorecida do Brasil. Isto pode ser devido a tendência que estas classes têm de utilizar planos de internet móvel restritos que disponibilizam acesso livre ao WhatsApp, mesmo quando o acesso liberado pelo plano se esgota. Então, muitas vezes, os usuários acabam por apenas ler as manchetes que lhes são enviadas e não o conteúdo ou fonte da notícia; tal aplicativo é a fonte de informação de $79 \%$ da população, de acordo com uma pesquisa realizada pelo Senado e Câmara Federal (TORRES, 2019); ainda, segundo a pesquisa realizada pelo Grupo Croma (O WHATSAPP..., 2019), 60\% dos usuários brasileiros utiliza o WhatsApp como ferramenta de trabalho, e 65\%, o utiliza antes de dormir. Esse modelo de acesso às notícias faz com que tais informações - muitas vezes, falsas - se espalhem mais rapidamente (VOSOUGHI; ROY; ARAL, 2018).

Esses dados referentes ao acesso às redes sociais, serviram como mote para que, por meio desta pesquisa, fosse investigado o uso destas, em sala de aula, por alunos da modalidade EJA, do CAp-UFRGS, delimitando-a aos alunos de três turmas do Ensino Médio (EM1, EM2 e EM3). Iniciamos a pesquisa com o intento de analisar a viabilidade - ou não - do uso das redes sociais e a importância do ensino das Tecnologias de Comunicação e Informação (TIC) nas escolas. Os resultados preliminares nos levaram a delimitar a pesquisa ao uso do Facebook, pois uma parte considerável dos alunos não possuía telefones celulares com espaço de armazenamento suficiente para instalar outros aplicativos, consequentemente decidimos pela não implementação do uso de outras redes sociais.

Na continuação, apresentamos a pesquisa denominada Revisão Sistemática de Literatura (RSL) realizada pela coordenadora desta pesquisa, juntamente com seus bolsistas, buscando saber se havia trabalhos publicados que faziam menção ao uso das redes sociais na Educação, incluindo as que fizessem este uso na modalidade EJA.

\section{Revisão bibliográfica}

Dentre as pesquisas publicadas, destacamos três, sendo duas delas sobre o uso das redes sociais na modalidade EJA.

Em sua tese de doutorado, intitulada A cultura dos usos das redes na academia: um olhar de professores universitários, brasileiros e italianos, sobre o uso das mídias na docência, a autora Rute Favero (2016) propôs-se a analisar o uso pedagógico das mídias sociais na docência. Tal pesquisa traz como justificativa a necessidade de compreender se e como os aplicativos que permitem criar redes sociais podem ser inseridos pedagogicamente em um contexto educacional. Sendo assim, a pesquisa mostrada nesta tese teve como objetivo, refletir sobre as possibilidades de uso das mídias sociais no âmbito acadêmico, tanto para professores brasileiros, quanto italianos. Foi diagnosticado que os professores brasileiros utilizam mais as redes em sala de aula do que os italianos, sendo, a maioria dos entrevistados, favoráveis ao uso destas e afirmando

1. Termo utilizado para se referenciar às notícias falsas veiculadas na internet, tendo sido cunhado nas eleições de 2016 , nos EUA, e incorporado ao vocabulário brasileiro durantes as eleições presidenciais de 2018. 
sua importância, além de acreditarem que é possível construir comunidades de aprendizagem nelas. A autora conclui que é fundamental o uso das redes, pois elas contribuem com a qualidade de ensino oferecido.

Além da pesquisa acima, dentre as 85 pesquisas encontradas em revistas, como a Revista Novas Tecnologias na Educação (RENOTE) e a revista Café com Sociologia de âmbito nacional, e em simpósios, como o $3^{\circ}$ Simpósio sobre Formação de Professores (SIMFOP) e 23 Simpósio Brasileiro de Informática na Educação (SBIE), que fizessem menção ao uso das redes sociais em sala de aula, destacamos um artigo e um ensaio que enfocam na modalidade EJA - foram encontrados apenas estes dois. O artigo publicado na Revista Linkscienceplace, intitulado "Celular como ferramenta de aprendizagem na EJA: análise do nível de consciência ambiental dos alunos" (BARRETO; NETO, 2015), reflete sobre a utilização das tecnologias digitais de informação e comunicação no processo de educação em relação a consciência ambiental. Tal estudo se mostrou favorável ao uso das tecnologias devido ao seu caráter facilitador. $\mathrm{O}$ ensaio, intitulado "As redes sociais e a educação: o uso do Facebook na modalidade de educação de jovens e adultos do SESI em Santa Catarina" (CORDOVA; FAVRETTO, 2014), discorre sobre o uso do Facebook como ferramenta tecnológica e pedagógica no processo de ensino e aprendizagem da EJA; tal utilização se mostra benéfica, por ser um espaço onde se pode disseminar boas práticas e experiências educacionais, e também ser um bom recurso para o processo de ensino e de aprendizagem.

Paralelo à pesquisa RSL, iniciamos a pesquisa apresentada neste artigo, cuja metodologia utilizada será apresentada abaixo.

\section{Método}

Quando surge um problema para o qual ainda não se tem uma resposta, pode-se optar pela investigação científica. Conforme Köche (2006, p. 30), "a investigação científica é a construção e a busca de um saber que acontece no momento em que se reconhece a ineficácia dos conhecimentos existentes, incapazes de responder de forma consistente e justificável às perguntas e dúvidas levantadas". Portanto, reconhecendo a inexistência de respostas adequadas quanto à utilização das redes sociais na modalidade EJA, foram selecionadas as abordagens qualitativa e quantitativa para buscar as respostas desejadas.

Por se tratar de um assunto relevante para determinada parte da sociedade e pelo fato de que uma das autoras deste artigo é professora de alunos na modalidade EJA, optamos por realizar a pesquisa com estes sujeitos, os quais podem se repetir no decorrer dos semestres, com as turmas evoluindo de EM1, para EM2 e, de EM2 para EM3; mesmo tendo o ingresso de novos alunos nas três turmas, mas sempre um público com características comuns - alunos da EJA, do CAp-UFRGS. Pela praticidade de uso, foram elaborados questionários online, o que nos possibilitaria obter respostas que poderiam trazer luz aos nossos questionamentos, uma vez que, segundo Gil (1991, p. 143), um questionário pode ter um número mais ou menos elevado de questões, as quais têm por objetivo "o conhecimento de opiniões, crenças, sentimentos, interesses, expectativas, situações vivenciadas, etc.” dos respondentes.

A delimitação dos questionários a perguntas, principalmente voltadas ao uso do Facebook, se deu por meio de resultados preliminares da pesquisa onde foi destacada a preferência dos alunos pelo uso desta rede, o Facebook, em contexto escolar, pois são raros os alunos com perfis em redes sociais como Instagram e Twitter. Mesmo com a oferta de utilização destas redes em sala, os alunos não se mostraram dispostos a criar perfis nessas redes, alguns devido à falta de espaço ou compatibilidade dos dispositivos celulares com os aplicativos.

A pesquisa foi desenvolvida no período de 2017 a 2020/1, e a aplicação dos questionários foi realizada antes do início da quarentena que estamos vivenciando, no Brasil, devido à pandemia mundial causada pelo Coronavírus, sendo assim, não se debruça no que concerne às aulas a distância implementadas, no Brasil, desde então. 


\section{Participantes}

Os participantes deste estudo foram - e alguns ainda são - alunos do Ensino Médio da EJA, do CAp - UFRGS, na faixa etária entre 18 e 80 anos, mulheres e homens, de etnias variadas, preponderantemente de baixa renda. Os alunos - totalizando, aproximadamente, 300, nos quatro semestres - foram convidados a responderem aos questionários, tendo a liberdade de se negarem. Destes, 186 respondentes ${ }^{2}$ aceitaram o convite. Cabe observar que a modalidade EJA não funciona da mesma forma que a regular; nela, um semestre equivale a um ano do regular, então os 3 anos de Ensino Médio regular são cursados em um ano e meio, na EJA.

\section{Recursos utilizados e coleta de dados}

Um elemento muito importante para delinear a pesquisa é o procedimento adotado para a produção de dados (GIL, 1991). Uma possibilidade é a aplicação de questionários como uma das técnicas para se obter as respostas desejadas, a fim de responder ao problema proposto, uma vez que é possível alcançar um maior número de pessoas. Razão essa, por termos adotado esta técnica, para a pesquisa aqui apresentada.

Foi criado, em 2017/2, um questionário, na plataforma Google Forms, com 18 perguntas que foram aplicadas aos alunos EJA. Conseguinte, este questionário foi adaptado e foram acrescentadas 8 perguntas, o qual foi aplicado, em 2018/2. Após nova revisão, buscando ter mais subsídios quanto à visão dos alunos sobre o assunto, adaptamos o questionário, deixando-o com 32 perguntas - sendo 4 dissertativas e 28 objetivas - e foi aplicado nos semestres 2019/1 e 2019/2, totalizando 186 respondentes. Contudo, cabe dizer que, neste trabalho, foram utilizadas somente as respostas das perguntas que eram pertinentes ao que se propusera esta pesquisa. Salientamos que a adaptação foi necessária, para podermos aumentar o espectro da pesquisa, sem, contudo, invalidar as respostas anteriores. Para realizar a tabulação, a verificação e a análise das respostas, foi utilizada a planilha do Google.

Também, convém salientar que, ao adotarmos a triangulação de dados - estudo longitudinal, acompanhando os alunos em semestres consecutivos -, conseguimos obter uma melhor compreensão da vivência dos sujeitos desta pesquisa, sobre o uso das redes sociais em sua vida acadêmica e pessoal, a longo prazo, possibilitando que os dados produzidos fossem analisados de forma mais apurada e detalhada.

\section{Análise}

Buscando realizar uma análise mais consistente dos dados produzidos, adotamos a triangulação entre as abordagens metodológicas qualitativa e quantitativa e a Análise de Conteúdo, que ofereceu elementos para subsidiar a pesquisa quantitativa.

A abordagem quantitativa foi empregada, uma vez que os dados obtidos com a aplicação dos questionários foram analisados através de categorias delineadas, conforme foram surgindo padrões que permitissem uma categorização.

Também, foi empregada a abordagem qualitativa, pois "as abordagens qualitativas se conformam melhor a investigações de grupos e segmentos delimitados e focalizados, de histórias sociais sob a ótica dos atores, de relações e para análise de discursos" (MINAYO, 2010, p. 57); definição que se aplica à pesquisa aqui apresentada.

Isto posto, salientamos que a decisão recaiu sobre tais abordagens, uma vez que em nossos questionários houve dois tipos de respostas que demandaram análises diferentes. As respostas referentes às perguntas

2. Chamamos de respondentes, pois um aluno pode ter respondido mais de uma vez, durante os três semestres que, teoricamente, permanece como aluno do CAp-UFRGS. 
de múltipla escolha foram analisadas, fazendo-se uso dos gráficos desenvolvidos na planilha Google, em que foi possível compreender as opiniões dos sujeitos, as quais foram separadas em categorias, de acordo com suas opiniões, bem como permitiu ter uma percepção do ponto de vista predominante. Por outro lado, as respostas descritivas não apenas complementaram o estudo, mas também abriram possibilidades para explicar e interpretar a realidade dos alunos EJA inseridos nas redes sociais, e como se dá esse contato; e foram separadas em categorias para termos uma análise mais precisa.

A seguir será apresentada a análise realizada com os dados produzidos, observando-se as respostas obtidas, após a aplicação dos questionários, além de fazermos relações comparativas destas respostas, entre os semestres.

\section{Análise e comparação}

O primeiro questionário aplicado às turmas da EJA foi ao final do período letivo de 2017, sendo readequado para sua aplicação, em 2018, e novamente, em 2019 (já com questões abertas); portanto, o questionário foi aplicado em 4 semestres para 12 turmas. Lembrando que, por exemplo, os alunos que iniciaram no primeiro semestre do Ensino Médio (EM1), em 2018/2, podem ter continuado até concluírem o Ensino Médio e, portanto, podem ter respondido, também, em 2019/1 e 2019/2. Salientamos, novamente, que as novas versões do questionário foram revisadas e melhor adaptadas ao contexto da pesquisa. Destes questionários, extraímos as respostas mais relevantes para a compreensão da perspectiva dos alunos sobre a utilização das redes sociais como ferramenta para aquisição de conhecimento, além da percepção dos mesmos quanto ao uso das redes sociais em sala de aula e em seu cotidiano. Nesta seção analisaremos e compararemos as respostas obtidas por meio destes quatro questionários.

Primeiramente, buscamos verificar se os alunos utilizavam ou acreditavam ser possível utilizar o Facebook como uma ferramenta de pesquisa para assuntos relacionados às aulas. Na Tabela 1, pode-se ver que $68 \%{ }^{3}$ dos alunos afirmaram que pesquisavam no Facebook assuntos referentes às aulas. Em 2018, o percentual aumenta em 13\%, tendo $81 \%$ de respostas afirmativas. Já no ano de 2019 , para esta mesma pergunta, obtivemos, no primeiro semestre, $91 \%$ dos alunos afirmando que utilizaram as redes para se informar sobre as aulas, e, em 2019/2, o percentual foi de $92 \%$, tendo um crescimento de $25 \%$ de respostas afirmativas entre os questionários, isto é, de semestre a semestre.

Tabela 1 - Você utilizou ou acredita que possa utilizar o Facebook para pesquisar algum assunto referente às aulas, durante $O$ ano de $201 X / X$ ?

\begin{tabular}{cccc}
\hline 2017 & 2018 & $2019 / 1$ & $2019 / 2$ \\
$68 \%$ & $81 \%$ & $91 \%$ & $92 \%$ \\
\hline
\end{tabular}

Fonte: Elaborada pelas autoras (2020).

Conseguinte, questionamos porque os alunos não utilizaram o Facebook como ferramenta de pesquisa (Tabela 2). Das respostas obtidas, $38 \%$ dos alunos responderam que não pensam nessa possibilidade; $31 \%$ afirmaram que não confiam no conteúdo presente no Facebook; $19 \%$ disseram não saber como fazer pesquisas nesta rede; $6 \%$ responderam que não acreditam que o Facebook tenha conteúdos relevantes para as aulas e $7 \%$ disseram não o fazer pois lhes faltavam tempo, principalmente devido ao trabalho.

3. As porcentagens são aproximadas, uma vez que foram arredondadas, conforme os preceitos matemáticos. 
Tabela 2 - Por que você não procurou, no Facebook, sobre conteúdos de aula?

Nem pensei nessa possibilidade.

$38 \%$

$31 \%$

Não confio nos conteúdos postados no Facebook (páginas, grupos, etc.)

$19 \%$

Não saberia como realizar uma pesquisa destas no Facebook.

$7 \%$

Falta de tempo.

$6 \%$

Fonte: Elaborada pelas autoras (2020).

Em 2019, a perspectiva de uso das redes sociais para aquisição de informações aumentou, como é possível ver na Tabela 3. Dos alunos respondentes, $89 \%$ deles acreditam no uso das redes para pesquisa, principalmente se relacionadas aos conteúdos vistos em aula; já, apenas $11 \%$ responderam negativamente.

Tabela 3 - Independentemente de utilizar, você considera que o Facebook possa ser utilizado para pesquisar assuntos, principalmente referentes às aulas (em páginas, grupos ou perfis)?

\begin{tabular}{ll}
\hline Sim & Não \\
$89 \%$ & $11 \%$ \\
\hline
\end{tabular}

Fonte: Elaborada pelas autoras (2020).

Ainda relacionado a informações referentes às aulas, foi questionado aos alunos qual era a frequência de uso dos grupos criados para subsidiar as disciplinas para a obtenção de informações de conteúdo. Tais grupos foram criados por alguns professores para a inserção dos conteúdos abordados em sala de aula, principalmente para que os alunos tivessem acesso fora desta, mas também para se criar um espaço de debate. Com isso obtivemos, em 2017, como mostra a Tabela 4, um percentual de 38\% de respostas informando que os grupos do Facebook são utilizados diariamente para atualizações; $24 \%$ semanalmente; 16\% esporadicamente; nunca com 14\%; quinzenalmente com 5\%; e 3\% responderam mensalmente. Já em 2019/1, 52\% dos alunos responderam que usavam os grupos diariamente, $24 \%$ esporadicamente, $21 \%$ semanalmente e 3\% mensalmente. Em 2019/2, 70\% responderam diariamente, 22\% semanalmente e 4\%, mensalmente e esporadicamente. O uso diário aumentou em $32 \%$ desde o primeiro questionário. Tais dados reforçam como a utilização dos grupos foi crescendo exponencialmente ao longo dos anos, aumentando sua importância.

Tabela 4 - Com que frequência você utilizou o Facebook para se comunicar com professores ou sobre assuntos relativos às aulas?

\begin{tabular}{lccc}
\hline & $2017 / 1$ & $2019 / 1$ & $2019 / 2$ \\
\hline Diariamente & $38 \%$ & $52 \%$ & $70 \%$ \\
Semanalmente & $24 \%$ & $21 \%$ & $22 \%$ \\
Quinzenalmente & $14 \%$ & $0 \%$ & $0 \%$ \\
Mensalmente & $3 \%$ & $3 \%$ & $4 \%$ \\
Esporadicamente & $16 \%$ & $24 \%$ & $4 \%$ \\
Nunca & $14 \%$ & $0 \%$ & $0 \%$ \\
\hline
\end{tabular}

Fonte: Elaborada pelas autoras (2020).

$\mathrm{Na}$ sequência, em 2018, questionamos os alunos se eles acreditavam que o Facebook poderia ser um espaço de aprendizagem complementar à sala de aula. É possível observar, na Tabela 5, que $93 \%$ - um percentual elevado - dos alunos disseram que sim, isto é, eles acreditam que esta rede pode representar um espaço adicional ao usado nas aulas convencionais e nela ocorrer momentos de aprendizagem. Já, em ambos os semestres de 2019, 100\% dos alunos afirmaram acreditar que o Facebook poderia ser utilizado como espaço de aprendizagem, tendo crescimento de $7 \%$. 
Tabela 5 - Você considera que as redes sociais podem ser um espaço de aprendizagem complementar aos conteúdos vistos em sala de aula?

\begin{tabular}{lc}
\hline Sim & Não \\
$93 \%$ & $7 \%$ \\
\hline
\end{tabular}

Fonte: Elaborada pelas autoras (2020).

Em 2017, 84\% dos alunos (Tabela 6) responderam que acreditavam que o Facebook pode ser um espaço para subsidiar as aulas e, com isso, auxiliar no processo de aprendizagem. Em 2018, tivemos $81 \%$ de respostas afirmativas. Em 2019, no primeiro semestre, 100\% dos alunos do primeiro semestre disseram que sim. Enquanto vemos que $97 \%$ dos alunos, no segundo semestre, afirmaram que sim. Mesmo com decréscimo de 3\% entre os dois semestres de 2019 - onde os alunos não justificaram de forma clara o porquê de sua resposta, apenas afirmando que o Facebook não lhes ajudou —, tivemos um crescimento de $13 \%$ do primeiro questionário ao último.

Tabela 6 - Você acredita que as redes sociais podem ser um espaço de auxílio às aulas?

\begin{tabular}{lcccc}
\hline & 2017 & 2018 & $2019 / 1$ & $2019 / 2$ \\
\hline Sim & $84 \%$ & $81 \%$ & $100 \%$ & $97 \%$ \\
Não & $6 \%$ & $19 \%$ & $0 \%$ & $3 \%$ \\
\hline
\end{tabular}

Fonte: Elaborada pelas autoras (2020).

Posteriormente, foi questionado - perguntas com respostas dissertativas — porque os alunos concordavam, ou não, com o uso das redes em sala de aula, como um recurso complementar às aulas presenciais. Das principais respostas, foi identificado que os alunos acreditam que por meio das redes sociais eles podem encontrar auxílio extraclasse e resolver dúvidas referentes às aulas de forma mais imediata, como afirmado pelo aluno $A 1^{4}$, que justifica a escolha positiva, dizendo que é "porque se você precisa de um auxílio do professor, ao invés de esperar o outro dia para ir à aula e perguntar pra professora você pode mandar uma mensagem". Também o aluno A2, vê que o uso das redes sociais para subsidiar às aulas é uma estratégia positiva, pois "para as pessoas que têm acesso às redes sociais é muito bom ter uma continuação dos trabalhos que foram dados em aula" sendo mais uma possibilidade de acesso ao conhecimento, porém, isso não o impede de fazer uma reflexão sobre a desigualdade existente entre seus colegas, uma vez que, apesar de ser um método válido de estudo, A2 lembra que "nem todos tem acesso às redes sociais" é uma reflexão que deve ser levada em conta, ao se pensar nos usos pedagógicos das redes sociais, pois a escola deve se adaptar aos meios dos alunos e tentar organizar seus métodos de forma democrática e coerente de acordo com as experiências e vivências de seus alunos, como salienta o aluno A3, ao dizer que o "método de ensino deveria se aproximar ao máximo da realidade cotidiana do aluno", uma vez que, segundo ele, "hoje, a realidade cotidiana do aluno envolve as mídias sociais. Não as utilizar no modelo de ensino é empurrar o aluno pra fora da sala de aula, é não falar o mesmo idioma dele, é não viver no mesmo mundo que ele", deixando mais clara qual é a importância da inserção das redes sociais na metodologia de ensino. Contudo, alguns alunos discordam do uso, pois as redes podem "tirar a atenção da aula" por dar a possibilidade de os "alunos responderem aos colegas/amigos", como foi a resposta dada pelo aluno A4. É importante ressaltar que o uso das redes deve "depender do assunto que está em aula, pois a internet ajuda, mas também prejudica", segundo o aluno A5.

Quando questionados, em 2017, sobre se haviam percebido diferenças entre as aulas que usam e as que não usam as redes sociais, 78\% afirmaram que sim, como é possível ver na Tabela 7. Já, em 2019, no

\footnotetext{
4. Para preservar a identidade dos alunos optamos por substituir os nomes pela letra A, seguida de um número para distingui-los:

A1, A2..., An.

5. As respostas tiveram sua ortografia corrigida, contudo sua essência foi preservada.
} 
primeiro semestre, obtivemos $78 \%$ de respostas afirmativas; enquanto, no segundo, semestre tivemos $69 \%$ de respostas afirmativas, tendo um decréscimo entre 2017 e 2019/1 de 0,3\% e, de 2019/1 para 2019/2, de 9\%.

Tabela 7 - Você percebeu alguma diferença entre as aulas que utilizam e as que não utilizam celulares em sala de aula?

\begin{tabular}{lccc}
\hline & 2017 & $2019 / 1$ & $2019 / 2$ \\
\hline Sim & $78 \%$ & $78 \%$ & $69 \%$ \\
Não & $22 \%$ & $22 \%$ & $31 \%$ \\
\hline
\end{tabular}

Fonte: Elaborada pelas autoras (2020).

Foi então requisitado aos alunos que explanassem quais as diferenças que eles perceberam nas aulas que usaram as redes. Em 2017, o principal ponto positivo das redes, segundo os alunos, foi a facilidade ao acesso de informações, uma vez que conseguiram "maiores informações do que conseguiriam apenas nos livros, pois atualmente as redes são mais acessíveis e rápidas em informações", como relatado pelo aluno A6. Ainda, é possível destacar como as redes sociais podem ser vantajosas quando se trata do seu uso para comunicação, visto que, durante o período de aulas, "facilitaram a comunicação com alguns professores", salienta o aluno A7. E para o aluno A8, quando utilizadas dentro da sala, deixam as "aulas muito interessantes, com debate e a turma interagindo em aula". Também é destacado que as aulas ficam mais produtivas, pois as mídias sociais agilizam e facilitam as pesquisas que devem ser feitas em ambiente escolar, já que é "tudo mais rápido, mais ágil, facilita muito nosso tempo. Gostei muito", além de possibilitar que tenham "mais produtividade", segundo as respostas dadas pelos alunos A9 e A10, respectivamente.

Além disso, foi destacado pelos alunos, em ambos os semestres de 2019, a importância das redes sociais quanto à facilidade de acesso à informação, pois "o manuseio das redes sociais, ajuda no aprendizado de outras informações", segundo o aluno A11, e abrem um vasto "leque de conhecimentos" para ser explorado, segundo o aluno A12.

Encerrando esta análise, apresentamos uma pergunta existente no questionário de 2019 (Tabela 8), em que foi questionado aos alunos se eles recomendariam o uso das redes sociais em sala de aula. No primeiro semestre de 2019 , tivemos $86 \%$ de respostas afirmativas, sendo que, dos principais argumentos a favor, o acesso à informação e à comunicação foi bastante salientado, já que servem "para se atualizar, obter mais conhecimento e ter um auxílio extra", conforme o aluno A13 e, para o aluno A14, "as redes sociais nos oferecem diversas plataformas para que possamos fazer pesquisas, trabalhos, e nos comunicar com os demais".

No segundo semestre de 2019, obtivemos 95\% de respostas afirmativas, sendo a principal justificativa, também, a comunicação e o acesso à informação, ambos utilizados com relativa frequência pela maioria dos alunos, uma vez que consideram as redes sociais "uma ferramenta muito rica, e de grande auxílio na aprendizagem", segundo o aluno A15. Corroborando, diz o aluno A16 que as redes sociais permitem "uma melhor comunicação entre aluno e professor, no desenvolvimento do conteúdo apresentado em aula".

A principal causa das respostas negativas é referente à distração que o uso das redes sociais pode causar aos colegas que a estariam usando e aos que sentam próximo a estes.

Tabela 8 - Você recomendaria o uso das redes sociais como complemento às aulas?

\begin{tabular}{lcc}
\hline & $2019 / 1$ & $2019 / 2$ \\
\hline Sim & $86 \%$ & $95 \%$ \\
Não & $14 \%$ & $5 \%$ \\
\hline
\end{tabular}

Fonte: Elaborada pelas autoras (2020).

Nesta análise, foi apresentado um viés da pesquisa que vem sendo realizada com os alunos da EJA, do CAp-UFRGS, sobre o imbricamento das mídias sociais e a Educação, no fazer docente, que, por vezes, apresenta caminhos áridos, "quase desesperançosos", nas palavras de Favero (2016, p. 193), mas, segundo 
a autora, sempre existem "possibilidades diversas de fazer educação" (p. 194); assim, a seguir, faremos uma rápida explanação a respeito da escolha ter recaído sobre o Facebook e como este foi utilizado em sala de aula.

\section{A implementação do Facebook}

Os dados apresentados na análise corroboram a ideia de que o uso do Facebook, como uma ferramenta didática, é válido, portanto, é importante se ressaltar as formas pelas quais ele pode ser utilizado, uma vez que esta plataforma, que permite o surgimento de redes sociais, se mostra mais do que, apenas, uma ferramenta de socialização. A criação de grupos fechados, em que somente os alunos de cada turma podem ter acesso, são aceitos como um espaço adicional à sala de aula, portanto, é um espaço em que os alunos se sentem à vontade para exporem suas ideias, suas dúvidas; é onde podem ocorrer interações dialógicas entre eles, educandos, e entre educandos e educador.

Para os alunos do Ensino Médio da EJA, do CAp-UFRGS, foram criados grupos para cada turma, em que eram criados posts com a indicação do que seria visto em aula e, quando possível, algum link ou material (vídeo, arquivo, meme, imagens, etc.) para que os alunos já pudessem ir se familiarizando. Após a aula, eram postados materiais que efetivamente foram usados, como links de pastas do Google Drive, em que estavam apresentações ou outros materiais utilizados, além de uma lista de assuntos tratados. Assim, os alunos que não puderam estar na aula, poderiam acompanhar o que havia sido tratado na aula. No caso dos poucos alunos que não possuíam perfil no Facebook, os próprios colegas enviavam tais links a eles, utilizando o WhatsApp. As postagens eram acompanhadas pelos alunos, os quais interagiam comentando, questionando, sugerindo novos links ou materiais de estudo, ou, simplesmente, curtindo. Também era solicitado que os alunos fizessem postagens sobre determinado assunto, mas que analisassem o que buscavam, a fim de não postarem informações incorretas - fake news. Os alunos eram levados a pensarem criticamente sobre o que cada um postava, inclusive sobre as postagens realizadas pela professora.

Favero (2016) explica que, apesar de ser visto apenas como uma ferramenta que subsidia as aulas, que poderia ser utilizada apenas com o intuito de postar trabalhos e temas, o Facebook não pode ser deslegitimado como meio de aprendizagem e partilha de conhecimentos, e destaca com base nos ensinamentos propagados por Freire e por Piaget que "um sujeito não aprende sozinho, mas, sim, somente a partir do momento que aprende a agir cooperativamente, na relação com o outro, e estes podem dialogar na busca de um novo conhecer, fortalecendo as trocas que ocorrem" (FAVERO, 2016, p. 189-190).

Isto quer dizer que, como ressaltado nas falas dos participantes dessa pesquisa, o Facebook pode ser utilizado para dialogar e criar um espaço de interação intelectual entre os alunos, compartilhando saberes, esclarecendo sobre as fake news, dentre tantas outras possibilidades. Pode-se criar um ambiente aquém da sua proposta inicial de socialização. O filósofo Pierre Lévy traz exemplos de utilização das redes no seu fazer docente, em entrevista para o site Extra, quando lhe foi perguntado sobre como ele agia com os alunos. Ele responde:

\footnotetext{
Abro um grupo no Facebook e os convido para fazerem uma seleção de conteúdo. Eles têm que publicar algum conteúdo, que seja relevante e conectado com o assunto da aula, com um pequeno comentário. Também crio subgrupos no Facebook para os alunos discutirem questões particulares e ajudarem uns aos outros. Peço para me seguirem no Twitter e me indicarem materiais importantes relacionados com pontos que vimos em sala de aula. Além disso, os convido a entrar no Schoolpix, que é uma ferramenta de conteúdo. Há várias na internet, essa é só um exemplo. Esse conjunto de ações é um dos melhores jeitos de o aluno explorar os múltiplos recursos de fontes e botar em prática alguma responsabilidade em escolher as informações e as fontes certas e o jeito de organizá-las. É importante escolher e categorizar as informações. Não ser apenas um consumidor de informações. (LÉVY, 2014).
}

Assim, como afirmado pelo filósofo, os alunos põem em prática o ato de pensar e refletir sobre suas ações e postagem dentro desses grupos. Se dá a esses alunos um espaço onde eles podem se expressar e 
compartilhar seus pensamentos de forma mais aberta sobre o que veem e aprendem em sala de aula, criando um espaço onde "o educador democrático, que aprende a falar escutando, é cortado pelo silêncio intermitente de quem, falando, cala para escutar a quem, silencioso e não silenciado, fala" (FREIRE, 2007, p. 117). Se cria o espaço onde todos podem ser ouvidos, onde a reflexão une os participantes, principalmente os professores com os alunos que constroem

[...] uma relação igualitária e colaborativa com o docente, em que prevalece o sentido das trocas, da participação e do dialogar, uma vez que "quando a pessoa do outro se torna um objeto independente, isto é, permanente e autônomo, as relações entre eu e os outros não são mais simples relações da própria atividade com um objeto exterior: eles começam a se tornar relações verdadeiras de troca entre o eu e o outro". (PIAGET, 2014, p. 94).

Cabe ressaltar que o uso das mídias sociais, seja em que área for, já está posto, isto é, esta é uma mudança que vem ocorrendo não apenas nas escolas, mas na sociedade como um todo. Corroborando e acompanhando estas mudanças, Pireddu acrescenta que

[...] o novo ecossistema das mídias obriga a repensar não somente os métodos, mas também as mesmas filosofias de ensino que ainda moldam a educação. No ambiente de mídia contemporâneo feito de informações ilimitadas e imediatas, [...] educadores nem sempre entendem que para o aluno é cada vez menos importante armazenar ou recuperar informações: hoje é cada vez mais importante ser capaz de encontrar, classificar, analisar, compartilhar, discutir, criticar e criar informações. (PIREDDU, 2014, p. 152).

Encaminhando-nos para a discussão final, é importante que se tenha em mente que a ferramenta, por si só nada faz, nada oferece; é o educador que deve saber qual uso dar a ela, seja uma rede social qualquer, seja uma sala, onde lhe é oferecido só um quadro e giz para que possa ministrar suas aulas.

\section{Resultados e discussão}

Com este estudo, foi possível diagnosticar a importância da utilização das redes sociais em sala de aula. Destaca-se, principalmente, a necessidade de as instituições de ensino estarem conectadas às redes sociais, pois, desde o princípio desta pesquisa, pudemos averiguar que grande parte dos alunos já utilizava as redes sociais para buscar informações, dando-lhes grande credibilidade como fonte de pesquisa; nem sempre tendo um olhar crítico para o que encontravam. Como visto anteriormente, é esta falta de conscientização e criticidade que leva as pessoas a repassarem as fake news; quando elas mesmas não as criam, com base em outras informações não idôneas.

Porém, também vimos que boa parte dos alunos, ao final do semestre de 2017, utilizava as redes, principalmente em sala de aula, para interagirem nos grupos, criados pelos professores, no Facebook, com o intuito de subsidiar as disciplinas. É importante que se destaque este ponto, pois demonstra um uso saudável das redes para obtenção de informações, uma vez que os grupos são supervisionados pelos professores. Com isso, os professores têm a oportunidade de mediar a obtenção de conhecimento por meio da internet e ainda de se inserir na realidade dos alunos.

Também foi constatado que os alunos passaram a considerar as redes um lugar que poderia ser utilizado como espaço de aprendizagem, podendo ser complementar às aulas. Ainda, foi ressaltado diversas vezes nas respostas dos alunos, que as redes sociais permitem que eles tenham acesso a mais informações e conteúdos de forma prática. Aferiu-se, portanto, que o uso das redes sociais possibilita um aumento na comunicação entre alunos e professores, complementando os assuntos tratados em sala de aula e proporcionando que entendessem mais claramente como utilizar as redes sociais de forma segura. Isto foi perceptível no decorrer dos semestres, em sala de aula - componente Cultura Digital -, e por meio das respostas 
obtidas nos questionários subsequentes; onde os sujeitos da pesquisa se demonstram mais conscientes e críticos perante o uso das redes sociais, permitindo aferir que houve crescimento no nível de conhecimento.

$\mathrm{O}$ uso das redes sociais em sala de aula possibilita que estas sejam mais dinâmicas e atrativas para os alunos, facilitando na hora de pesquisar sobre os conteúdos apresentados em aula; sendo assim, preferidas pela maioria dos alunos, mesmo com as possíveis inconveniências que alguns consideram que o uso das redes pode trazer. Ainda, vale ressaltar que as redes estão presentes na vida dos alunos, independentemente de serem usadas, ou não, em um ambiente escolar, como foi ressaltado por vários alunos e demonstrado anteriormente em uma resposta dada por um deles.

Concluímos que é dever da escola se inserir no contexto social de seus alunos e ajudá-los a se tornarem cidadãos mais conscientes e com acesso à informação. Para isso, deve-se priorizar o uso das redes sociais no fazer docente, de forma contundente, para que os alunos saibam como melhor utilizá-las, a fim de buscar informações, além de contribuírem para a socialização e inclusão deles. Em sua pesquisa, Favero (2016, p. 195) apresenta um percentual elevado - $81 \%$ - de professores que "dizem considerar importante o uso das mídias sociais no Ensino/Aprendizagem" e acrescenta que "68\% (deles) acredita que seja possível construir comunidades nos ambientes oferecidos pelas mídias sociais"; percentuais estes que vem ao encontro daqueles apresentados pelos alunos da EJA, isto é, 80\% deles disseram usar o Facebook e 87\%, o WhatsApp, portanto "podemos acreditar que existam caminhos alternativos para uma educação, quiçá, pluridimensional".

Isto posto, consideramos que o uso adequado das redes sociais dentro da sala de aula irá colaborar para que os alunos tenham a chance de ampliar seus conhecimentos e fazer com que eles entendam onde buscar informações de forma segura. Assim, eles poderão passar aos seus filhos ou demais pessoas de seu convívio informações seguras, além de se tornarem mais capazes de ensinar aos mais jovens o uso cauteloso das redes sociais, contribuindo para que estes - e eles próprios - se tornem cidadãos conscientes e críticos das informações que obtêm.

Salientamos que, por ser uma pesquisa elaborada e aplicada anteriormente à pandemia causada pelo Coronavírus, ela não traz resultados pertinentes à atual situação do ensino a distância implementado, no Brasil. Contudo, estamos iniciando uma pesquisa para verificar como alunos e professores da rede pública metropolitana de Porto Alegre estão vivenciando este momento em que as aulas estão sendo oferecidas a distância, e em como estas tem acontecido, para termos respostas contundentes quanto ao uso das redes sociais dentro deste momento histórico específico.

\section{Referências}

BARRETO, Nayara Felix; NETO, Érica Pereira. Celular como ferramenta de aprendizagem no EJA: análise do nível de consciência ambiental dos alunos. Linkscienceplace - Revista Científica Interdisciplinar, Rio de Janeiro, v. 2, n. 4, p. 161-170, out./dez. 2015.

BÔAS, Bruno Villas. Classes sociais A e B voltam a crescer e atingem 14,4\% da população. Rio de Janeiro: Valor Social, 2019.

BRASIL. Lei de Diretrizes e Bases da Educação Nacional. Brasília, DF: MEC, 2017.

CORDOVA, Tania; FAVRETTO, Rosani Aparecida Dias. As redes sociais e a educação: o uso do Facebook na modalidade de educação de jovens e adultos do SESI de Santa Catarina. In: CONGRESSO INTERNACIONAL DE EDUCAÇÃO A DISTÂNCIA, 20., 2014, Curitiba. Anais [...]. Curitiba: ABED, 2014.

DELORS, Jacques. Educação um tesouro a descobrir: relatório para a UNESCO da Comissão Internacional sobre Educação para o século XXI. São Paulo: CORTEZ; Brasília, DF: UNESCO, 1998. Disponível em: http://ftp.infoeuropa. eurocid.pt/database/000046001-000047000/000046258.pdf. Acesso em: 21 jul. 2020.

FAVERO, Rute Vera Maria. A cultura dos usos das redes na academia: um olhar de professores universitários, brasileiros e italianos, sobre o uso das mídias sociais na docência. 2016. Tese (Doutorado em Educação) - Universidade Federal do Rio Grande do Sul, Porto Alegre, 2016.

FREIRE, Paulo. Pedagogia da autonomia: saberes necessários à prática educativa. São Paulo: Paz e Terra, 2007.

GIL, Antonio Carlos. Métodos e técnicas de pesquisa social. 4. ed. São Paulo: Atlas, 1991. 
IBGE. Pesquisa Nacional por Amostra de Domicílios Contínua. Rio de Janeiro: IBGE, 2018.

IBGE. Tábua completa de mortalidade para o Brasil - 2018: breve análise da evolução da mortalidade no Brasil. Rio de Janeiro: IBGE, 2019.

IDOSOS são mais propensos a espalhar notícias falsas, diz estudo. BBC News Brasil, São Paulo, 12 jan. 2019. Disponível em: https://www.bbc.com/portuguese/brasil-46849533. Acesso em: 5 jan. 2020.

KÖCHE, José Carlos. Fundamentos de metodologia científica: teoria da ciência e iniciação à pesquisa. 23. ed. Rio de Janeiro: Vozes, 2006.

LÉVY, Pierre. 'Só tablets não fazem o trabalho sozinhos', diz o filósofo Pierre Lévy. [Entrevista cedida a] Bruno Alfano. Extra, Rio de Janeiro, 3 ago. 2014. Disponível em: https://extra.globo.com/noticias/educacao/educacao-360/so-tablets-nao-fazem-trabalho-sozinhos-diz-filosofo-pierre-levy-13468681.html?ixzz3HgHN7GUa. Acesso em: 21 jul. 2020.

MINAYO, Maria Cecília de Souza. O desafio do conhecimento: pesquisa qualitativa em saúde. 12. ed. São Paulo: Hucitec, 2010.

OLIVEIRA, Inês Barbosa. As interfaces entre educação popular e educação para jovens e adultos: exigências de formação para a prática com esses grupos sociais. Educação, Porto Alegre, v. 33, n. 2, p. 104-110, maio/ago. 2010.

PIAGET, Jean. Relações entre a afetividade e a inteligência no desenvolvimento mental da criança. Rio de Janeiro: WAK, 2014.

PIREDDU, Mario. Social learning: le forme comunicative dell'apprendimento. Milano: Guerini Scientifica, 2014.

SANTOS, Fabiano Pereira dos; VIEIRA, Maciel Antoninho. Sobre a noção de moral provisória em Descartes. In: SEMINÁRIO DE INICIAÇÃO CIENTÍFICA, 24., Ijuí. [Anais...]. Ijuí: UNIJUÍ, 2016.

TORRES, Lívia. Pesquisa aponta que WhatsApp é a principal fonte de informações de 79\% dos entrevistados. Rádio Senado, Brasília, DF, 12 dez. 2019. Disponível em: https://www12.senado.leg.br/radio/1/noticia/2019/12/12/pesquisa-aponta-que-whatsapp-e-a-principal-fonte-de-informacao-de-79-dos-entrevistados. Acesso em: 5 jan. 2020.

VOSOUGHI, Soroush; ROY, Deb; ARAL, Sinan. The spread of true and false news online. Science, United States, v. 359, n. 6380, p. 1146-1151.

O WHATSAPP é o aplicativo mais acessado pelos brasileiros no celular. Grupo Croma, São Paulo, 2019. Disponível em: https://cromasolutions.com.br/o-whatsapp-e-o-aplicativo-mais-acessado-pelos-brasileiros-no-celular/. Acesso em: 23 jan. 2020.

Data de submissão: 22/06/2020

Data de aceite: 17/07/2020 